\title{
Experimentación con medios análogos y su aplicación como recurso audiovisual, reflejo de un contexto latinoamericano
}

\section{Clunes, Antonieta}

Resumen: El presente ensayo consiste en una lectura de la relación entre arte y tecnología a partir de los antecedentes históricos y técnicos que generaron su desarrollo como asimismo desde distintas aristas.

Palabras clave: Arte - Tecnología Cultura - Sociedad.

$\left({ }^{*}\right)$ Diseñadora y artista. Magister en artes, mención artes mediales. U de Chile. Postítulo en fotografía. Docente en las áreas de Estética e historia Universidad de Antofagasta e Instituto Profesional Santo Tomás.

El presente ensayo consiste en una lectura de la relación entre arte y tecnología a partir de los antecedentes históricos y técnicos que generaron su desarrollo desde distintas aristas. Por un lado se plantea cómo las tecnologías implican cambios culturales, y luego, más específicamente, cómo el campo del Cuadernos del Centro de Estudios de
Diseño y Comunicación No 66

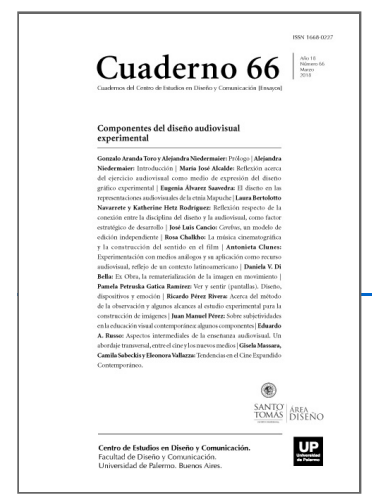

ISSN: 1668-0227

Componentes del

diseño audiovisual

experimental

Año XVIII, Marzo 2018, Buenos Aires, Argentina | 196 páginas

descargar PDF

ver índice de la publicación

Ver todos los libros de la publicación

compartir en Facebook

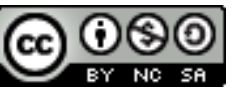

Esta obra está bajo una Licencia Creative Commons Atribución-NoComercialCompartirlgual 4.0 Internacional arte abarcará este tema desde una perspectiva occidental como canon cultural. A partir de ello, surge la necesidad de indagar en manifestaciones que no han sido consideradas dentro de esta oficialidad, pero que, sin embargo, sucedieron de manera contemporánea e incluso con antelación en Latinoamérica y que, por distintas circunstancias, ya sea por desconocimiento o por hegemonía cultural, han sido dejadas fuera de la historia. Se analizará también las circunstancias políticas, culturales y económicas que terminan por validar estos sistemas. Todas estas reflexiones surgen a partir del desarrollo de una obra que he realizado a partir del año 2014, la cual intenta proponer ciertas respuestas a dichas problemáticas.

Sociedad, cultura y tecnología

Es posible afirmar que uno de los aspectos que exponen la especificidad del ser humano como especie es la utilización de tecnologías, las cuales se definen como el conjunto de saberes y técnicas que le permiten modificar su entorno material, vale decir, el proceso combinado de intelecto y acción que le ayudan a encontrar soluciones a sus diversas necesidades. Desde los planteamientos de McLuhan, la tecnología puede ser entendida asimismo como una extensión del cuerpo, esto es, como la capacidad humana de generar artificios y herramientas.

Una primera etapa de desarrollo técnico está dada por la dominación del fuego y la creación del lenguaje, y posteriormente la escritura, hasta alcanzar la agricultura que conlleva un conjunto de conocimientos y técnicas como la creación de calendarios, técnicas de cultivo y la organización de sociedades más sofisticadas. Por su nivel de complejidad, la agricultura se considera el paso a una segunda etapa en el desarrollo de la humanidad. 
Si analizamos la historia desde una perspectiva material o técnica es fácil apreciar cómo la sociedad va cambiando en función de la creación de nuevas tecnologías. La colonización y posterior globalización se deben en gran medida a la creación del sextante y la brújula. La revolución copernicana, que inaugura el Renacimiento, no hubiese sido posible sin el desarrollo de la óptica que propició la creación de telescopios, tecnología fundamental para la generación de la teoría heliocéntrica, que implica un cambio de paradigma desde el teocentrismo al antropocentrismo. Asimismo, sin la imprenta de Gutenberg nunca se hubiesen expandido las ideas que llevarían posteriormente a la llustración.

Ahora bien, la máquina a vapor de James Watt marca el comienzo de una tercera etapa, dada por la instauración de la industrialización, que llega a su punto más alto en la época Victoriana, y que impone un sistema que implica un modo de producción y organización económica y social que servirá como modelo para toda la sociedad occidental, lo cual llevará a Europa a situarse como el nuevo imperio dentro del panorama mundial. Algunos de los cambios sociales que se producen son la migración campo-ciudad (que implica el alejamiento de la naturaleza para establecerse en centros urbanos industrializados), el surgimiento de nuevas clases sociales (burguesía y proletariado), entre otros.

Las fábricas se caracterizan por la automatización de los procesos de producción, o, como lo denomina Walter Benjamin, la reproductibilidad técnica. Esto quiere decir que los productos comienzan a elaborarse en serie a través de procesos automáticos previamente configurados, los cuales se complejizarán y se harán cada vez más sofisticados en relación a la optimización de los procesos productivos, sobre todo a partir de los descubrimientos e inventos de Edison y Tesla. Alan Turing, en el contexto de la segunda guerra mundial, crea el primer computador y, lo que nace con un objetivo bélico, va a ser el punto de partida de lo se denomina como la era digital. En este ámbito es posible nombrar a los satélites y la fibra óptica como otras contribuciones clave en la revolución digital.

Actualmente, el tiempo entre revoluciones tecnológicas va disminuyendo exponencialmente. Esto se debe al fácil acceso y transmisión de conocimiento que otorga la implementación de la World Wide Web, que permite que en distintos lugares se pueda acceder al conocimiento, y que la educación ya no sólo esté en manos de las instituciones. Por otro lado, los costes de adquisición de artefactos tecnológicos y herramientas digitales es más asequible en términos monetarios, hasta el punto en que hoy en día se incorporan automáticamente a la vida cotidiana, generando incluso una tecnofilia en los nativos digitales. No obstante lo anteriormente expuesto, la tecnología actual o digital, que es también llamada High tech o alta tecnología, continua siendo, como en los comienzos de la humanidad, una extensión de las articulaciones humanas, que continua modificando las maneras en las cuales se desarrolla el comportamiento humano.

\section{Arte y tecnología}

En una de las ideas centrales de la tesis de McLuhan sobre los medios de comunicación, afirma que formamos nuestras herramientas y luego éstas nos forman. Dicho de otro modo, toda tecnología termina por modificar o constituir el modo en que vivimos, nos comunicamos, nos representamos, etc. lo cual influye en los procesos y cambios históricos. Al mismo tiempo, y como consecuencia de tal impacto, los artistas comienzan a utilizar dichas tecnologías como medios de expresión. Tales procesos hacen surgir nuevas estéticas, gracias a las nuevas posibilidades de creación y desarrollo artístico.

Uno de los cambios estéticos importantes surge a partir de la invención de la fotografía, la cual libera a la pintura de su función de registro, generando una crisis en la representación visual. Hasta ese momento, las academias enseñaban a las artistas, técnicas para generar volumen a partir de la degradación de las sombras, técnicas de perspectiva, y otras normas, bastante estrictas, de cómo debía ser una pintura. En la medida en que la fotografía es capaz de cumplir de mejor manera tal imperativo académico, el impresionismo surge como la búsqueda de un modo de representación que obedezca a la realidad en tanto tal, y no como el resultado de una imposición referencial. Esta búsqueda llega a su punto más empírico en Seurat, quien incluso asiste a conferencias científicas sobre la teoría del color, y a partir de eso genera sus cuadros.

Posterior a los Impresionistas hubieron búsquedas hacia un lenguaje abstracto -como Picasso, en Las señoritas de Avignon-, donde aún es posible encontrar figuras y referentes identificables o concretos, pero no es sino hasta Malevic, cuando la abstracción logra dejar atrás todo elemento referencial para encontrar un lenguaje propio, libre de lo figurativo, donde cada obra plantea sus propias reglas y modos de lectura. Desde este punto, la pintura comienza a mirarse a sí misma, lo cual concibe que se planteen una serie de teorías sobre la pintura y las posibilidades de expresión que generan sus postulados, los cuales surgen ahora desde la pintura misma, y ya no desde el mundo exterior. Como ejemplo de ello es posible citar a Kandinsky, quien en su libro Punto y línea sobre el plano plantea teorías sobre la percepción de las figuras geométricas y las sensaciones que transmiten. También realiza obras que buscan generar una relación sinestésica al representar el sonido por medio de la pintura.

Ahora bien, la tecnología no solamente obliga al arte a cambiar sus modos de representación, sino que también aportan nuevos medios de expresión. Por ejemplo, en música, la invención del Theremin implica la utilización de las nuevas tecnologías análogas en la producción musical, generando nuevos sonidos. En la Bauhaus, MoholyNagy, crea las primeras esculturas cinéticas, cuyo movimiento es generado electrónicamente. En los años sesenta, Tingueli, en su obra Cyclograveur, también utiliza recursos electrónicos, pero cuestiona el rol de artista como productor de obras al generar una máquina que crea imá- genes de manera mecánica. 
A partir de la masificación de los medios de comunicación, dichos cambios suceden cada vez más rápido generando una serie de mutaciones sociales. Durante este mismo periodo, en los años cincuenta, gracias al invento de Turing, surge la tecnología digital, que proporciona nuevas herramientas para el desarrollo artístico. En 1962, el ingeniero Michael Noll genera la primera imagen en computador, a partir de un algoritmo, sin una utilidad práctica, la cual denomina como Gaussian Quadratic. En 1966, Ken Knowlton y Leon Harmon crean una imagen a partir de una foto escaneada, transformándola a código binario. La obra representa un desnudo, lo cual remite a un tema clásico de la historia del arte, planteando que el lenguaje digital es un nuevo medio de expresión, y que, por tanto, debe ser considerado como una plataforma válida para el desarrollo artístico. En los años sesenta, se funda el E.A.T (Experiment in Art and Technology), una organización que se establece para desarrollar colaboraciones entre artistas e ingenieros. Esta organización es un referente importante en la relación arte-tecnología, ya que los artistas pudieron tener acceso a las últimas tecnologías, generando obras en conjunto con programadores e ingenieros. A partir de ello, surgieron nuevos inventos, los cuales, en principio, eran un requerimiento técnico para las obras artísticas, pero que posteriormente se convirtieron en tecnología de consumo, como el control remoto, algunos sensores, y las cámaras infrarrojas.

Un hito importante en la propagación de la estética digital, está dada por la creación del programa computacional MacPaint (1984), diseñado específicamente como plataforma para el desarrollo de imágenes digitales, y predecesor de todos los software actuales para editar y producir imágenes. Posteriormente, en los años noventa, internet, que viene desarrollándose desde los años cuarenta (Arpa Net, Enniac), se masifica, y será utilizado también en el ámbito artístico. En el NET.ART, la web se usa como medio para crear obras en tiempo real conectando espectadores alrededor del mundo. Actualmente se realizan acciones artísticas en mundos virtuales. Con respecto a las instalaciones, el uso de sensores ha permitido crear situaciones inmersivas que cambian el lugar del espectador, situándolo ahora como interactor, es decir, como parte esencial en el desarrollo de la obra. En algunos ámbitos más específicos como el Arte Genético, es posible crear nuevas especies de seres vivos, crear esculturas utilizando cromosomas como materialidad y una infinidad de posibilidades impensables hasta hace algunos años atrás. Todo lo anteriormente descrito, revela la estrecha relación que existe entre arte y tecnología, en una relación de mutua influencia, generando nuevas ideas y modos de expresión basadas en la comunión de ambas disciplinas.

\section{La situación latinoamericana: Arte y tecnología en Latinoamérica}

Las maravillas de la era digital son tantas como sus contradicciones, por esto lo que se desarrollará en este apartado del texto, es un análisis desde una perspectiva latinoamericana, que plantea una manera distinta de afrontar la era digital y cuestionar si es posible generar una visión y maneras de creación propias. Uno de los temas centrales de la problemática sobre la identidad latinoamericana, está constituida por los diversos grados de dependencia que sostiene con occidente. Desde los procesos de conquista hasta la instauración final del capitalismo tardío, la manera en la cual el artista latinoamericano intenta encontrar una particularidad identitaria está siempre determinada por los grados de influencia que sostiene con el resto del mundo, dificultando de esta manera el hallazgo de los rasgos esenciales que podrían llegar a constituir una identidad particular.

En torno a ello, han surgido diversas soluciones. Algunas de ellas pretenden igualar o cuando menos aproximarse a los estándares europeos y estadounidenses; otras intentan desligarse completamente de su influencia, apelando a una autenticidad ligada a la cultura precolonial e indigenista; asimismo existen propuestas que median entre estos extremos, recibiendo la influencia cultural extranjera, pero al mismo tiempo cuestionándola y buscando subvertirla a partir de un contenido propio.

Ahora bien, para intentar despejar esta problemática, es importante destacar la condición material que los procesos coloniales han dejado en el continente. La promesa del bienestar y progreso que suponía implementar estos sistemas no se cumple, sino más bien genera pobreza y desigualdad, debido a que la condición latinoamericana, es distinta a la de los países donde se concibieron estos sistemas de producción. Todo ello genera como consecuencia una brecha entre los estándares de vida extranjeros y los del continente. Por otra parte las tecnologías y conocimientos que arriban a Latinoamérica están constante desfasados con respecto a los lugares donde se producen. Sin embargo, es posible destacar algunos casos de desarrollo tecnológico, en Latinoamérica, que no tienen como referente lo que estaba sucediendo en el resto del mundo. En 1971 durante el gobierno de Allende se crea el proyecto Synco o Cybersyn, que consiste en una red de máquinas de teletipo que tenían como objetivo transferir información desde las fábricas hacia un centro de cómputo en Santiago, de manera tal de facilitar la comunicación y el gestión de las fábricas chilenas. Para su funcionamiento utilizaba principios de cibernética en tiempo casi real. Cybernet fue una visionaria red de comunicaciones entre empresas y el gobierno, tal vez la primera de su género en el mundo. Sin embargo, nunca se llegó a implementar. Para su desarrollo se utilizaron 500 teletipos que estaban en desuso, lo cual sirve para dejar constancia de que es posible crear innovaciones tecnológicas que respondan o se adecúen a los recursos con los que se cuenta. Durante el siglo XX el acceso al conocimiento era difícil y aún más en los ámbitos artísticos que exploraban la relación arte-tecnología, como los descritos anteriormente. No obstante,se podría nombrar, por ejemplo, el caso del Abstractoscopio Cromáticoo Robot de la Pintura Abstracta del ingeniero Carlos Martinoya y el cristalógrafo Nahum Jöel,quienes en la década de los sesenta exhiben este dispositivo que genera proyecciones a través de cristales birrefringentes, generando juegos cromáticos. El trabajo de Martinoya y Jöel tiene la importancia de manifestar una exploración entre arte y tecnología. 
Otra de las personas que estaban explorando esta relación es Vicente Asuar, considerado uno de los precursores de la música electroacústica en Chile, quien en 1958 funda el primer laboratorio de música electrónica de América Latina en la facultad de Artes de la Universidad de Chile, donde compone Variaciones Espectrales, su primera obra electrónica. Posteriormente, en 1977, crea el Comdasuar, el primer ordenador chileno dedicado exclusivamente a interpretar música, con tecnología híbrida (análoga y digital).Bajo su propio testimonio, afirma que:

En 1973 para la realización del disco El Computador Virtuoso, tuvimos que construir algunos dispositivos que conectaran el computador con el sintetizador electrónico, y desarrollar un sistema que permitiese introducir al computador los datos de la partitura en la forma más sencilla, rápida y segura posible, para obtener de este los voltajes de comando al sintetizador y estructurar cada sonido según nuestros deseos. Esta es la primera experiencia hecha en Chile sobre la materia y el sistema que hemos creado es totalmente original sin que nos hayamos basado en ninguna experiencia anterior.

Esta tecnología lo instala como un visionario de la inteligencia artificial, ya que este dispositivo puede tomar decisiones independientemente del hombre.

Si bien los ejemplo anteriores manifiestan que en Latinoamérica hubo generación de tecnologías, resultan excepciones frente a la hegemonía cultural y estética del Euroamérica. Pareciera que cuando se persigue ese canon, que difiere de la realidad latinoamericana, se está destinado a ser la sombra de ellos, la copia o la versión pobre de lo mismo. Y aún peor, en ese afán de querer ser, se pierde de vista lo valioso que posee el continente.

El problema más grave que enfrenta Latinoamérica, no es la falta de posibilidades de crear tecnología, como se plantea comúnmente. El asunto va más allá de la falta de medios económicos, ya que la verdadera pobreza es perder identidad y es este el lado más oscuro de la globalización: La homogeneización cultural (Baeza, 2006), y por tanto estética y conceptual del mundo.

Una postura disidente pude ser asumir las condiciones que determinan a Latinoamérica: las carencias también definen y son parte de un estilo, reconocer aquello que identifica y diferencia como algo positivo para dejar de regirse por modelos estéticos que tienen un contexto absolutamente distinto, y construir a partir de una identidad propia.

Para fundamentar esta postura, es posible observar que existen otros artistas chilenos que no se han destacado en lo tecnológico, pero que sí han creado vanguardia en el ámbito intelectual, revolucionando con ideas y conceptos, donde una particular mirada mestiza fue lo que dio origen a un estilo propio. Por ejemplo, Vicente Huidobro, desarrolló el creacionismo a partir de un encuentro con un brujo mapuche. Nicanor Parra, recrea el Quijote en lenguaje coloquial y utilizando desechos y objetos encontrados para crear sus artefactos visuales. Alejandro Jodorowsky, plantea que la disciplina de la Psicomagia hunde sus raíces en el chamanismo (Psicomagia, 2005), el cual se mezcla con el psicoanálisis de Freud.

Actualmente los artistas de Low-Tech, ya sea por problemas de recursos o por ideología, trabajan con materiales encontrados y objetos cotidianos otorgando nuevos usos a desechos y a la alta tecnología de ayer, ahora obsoleta y la resignifican. Algunos ejemplos del movimiento son el proyecto LaMe, quienes trabajan colaborativamente desarrollando diversos dispositivos a partir del reciclaje tecnológico y el circuitbending. Chimbalab es otro punto de referencia en el panorama de las artes electrónicas en Chile. El eje del trabajo son los circuitos, el hackeo de aparatos, el reciclaje de baja tecnología. Los aparatos se reparan y se transforman, nunca se tiran. Otro caso lo constituye la "Máquina de coser", de Demian Schopf, expuesta en el marco de la Trienal de Chile. Esta obra, de aparente precariedad, representa en sí un ejemplo de arqueología medial, al reutilizar computadores antiguos quitando su carcaza y exponiendo de forma cruda sus compontes, abriendo la denominada "caja negra", exponiendo los medios que antes permanecían ocultos.

A partir de estos ejemplos, se infiere que en Chile existe un movimiento donde, más importante que el desarrollo de tecnología, es la reflexión sobre ellas, vale decir, el análisis de temáticas como: la tele vigilancia, la comunicación, el consumo, etc. Tenemos una manera de ver distinta a la de otros países Occidentales. Innovación no es sólo un dispositivo nuevo, también puede ser una idea, una manera de pensar, de ver, de apropiación, etc. Es posible crear vanguardia, formas estéticas y temáticas propias, si vemos nuestras circunstancias actuales, económicas y culturales, como un contexto que determina un estilo propio, reflejo intrínseco de nuestra sociedad y, por lo tanto, parte fundamental de nuestra identidad.

\section{Experimentación con los medios y su aplicación como recurso audiovisual}

En un comienzo, la función de los ordenadores era realizar cálculos matemáticos. Los primeros gráficos y dibujos por ordenador fueron realizados por los ingenieros y programadores que tuvieron acceso a ellos (Bense, Noll, Knowton y Harmon, Moles), que Wolf Lieser considera:

La primera piedra para llevar a cabo un nuevo desarrollo en el arte contemporáneo, destinado a cambiar el concepto de la estética en la vida cotidiana y la cultura posterior al posmodernismo, al igual que lo había hecho la fotografía en el siglo XX. (Lieser, 2009) 
A medida que el ordenador va evolucionando, y a la vez se vuelve más asequible, comenzará a ser utilizado con fines artísticos, para, progresivamente, ir instaurándose como una estética válida, llegando a convertirse en una herramienta común para el desarrollo del arte y el diseño.

Ahora bien, la producción de imágenes, en un solo día contemporáneo, supera el número de las acumuladas hasta el siglo XX. Ya no sólo los espacios públicos están atestados de publicidad, sino que esta continúa en los espacios privados, a través del ordenador, la televisión o los dispositivos móviles. La estética predominante de esta sobreproducción de imágenes es digital, entendida como aquellas manifestaciones artísticas llevadas a cabo con un ordenador, que en el fondo no son sino códigos binarios, vale decir, series electró- nicas de ceros y unos.

La producción de imágenes digitales pueden, como ya se ha visto, ser consideradas como un tipo de arte. El límite es difuso. Según Wolf Lieser, "la producción digital puede definirse como arte cuando conceptualmente se utilizan las posibilidades del ordenador o de internet con un resultado que no sería alcanzable por otros medios" (Lieser, 2009). Ahora bien, el exceso de la estética digital suplanta lo real por lo virtual. Lo análogo y lo manual se plantean, por ende, como un aspecto estético diferenciador.

Para esto lo que se propone es explicar un proyecto personal llamado Fotocassette1, expuesto en la Fundación Telefónica en el contexto del concurso Matilde Pérez de Arte y Tecnología,con el cual se busca replantear el uso de los medios, invitando al espectador a moverse en un espacio de especulación, en tanto que usa tecnología obsoleta de una manera totalmente distinta para la cual fueron creados, reinterpretando su mecánica. La obra consiste en un proyector que hace visual el sonido a partir de una cinta de cromo de cassette, con un segmento de una canción de Violeta Parra (la frase: "cambia todo en este mundo"), la cual es intervenida, y va desgastándose, perdiéndose y cambiando a medida que gira constantemente a modo de loop, dando como resultado una imagen en movimiento de textura análoga que nunca es la misma,creando una nueva lectura a modo de archivo fragmentado. En palabras de Daniel Cruz:

En la obra se rasguña el proceso de lo verbal por medio de la intervención de una cinta de música folclórica para intentar ocultar la operación a través del traspaso de la luz. Una especie de inversión lingüística; lo que se debiera escuchar, se ve. (Cruz, 2014)

Otra obra, que nace a partir de la anterior, implica la unión entre este dispositivo y una forma de animación de invención propia, que está inspirada en el teatro de sombras, pero que cambia el fondo estático característico de las animaciones de la antigua China por un fondo dinámico, a través de la incorporación de un mecanismo que hace circular cilindros de papel con ilustraciones hechas en tinta (a modo de papiros, enrollando el papel de un cilindro a otro situado en el otro extremo), otorgando dinamismo al contexto de la animación.

Esta máquina híbrida, realizada con tecnología obsoleta como walkmans, cassettes y mecanismos de bicicletas, ha sido utilizada como recurso gráfico en la realización de material audiovisual y videoclips, ya que crea imágenes aleatorias con una textura análoga única y con calidades e intensidades de luz que varían de manera aleatoria (https://vimeo. com/120363136). Se trata de una reinterpretación de medios antiguos con un toque contemporáneo, un vuelco experimental que otorga una estética particular e irreproducible que se diferencia de la estética digital predominante utilizada en el ámbito audiovisual. Estamos en un momento histórico donde no existen sistemas alternativos al presente. Es el momento de la hiper-modernidad sin oposición alguna, sin normativa o regulación y que tiene un estatus de global. El ordenador ha creado nuevos lenguajes estéticos, pero a poco tiempo de su aparición, ya se pierden o más bien se anulan por la sobreproducción que hay de este recurso. Este trabajo con tecnologías en desuso es tan sólo una propuesta. Es preciso buscar, en todo caso, modos alternativos de crear imágenes con una estética amparada en un agente diferenciador. Esta propuesta en particular pretende reflejar de manera honesta la relación obra-contexto, funcionando a la vez como crítica al consumismo, la obsolescencia y el extremo esteticismo al que aspiran algunas obras contemporáneas, demostrando que la carencia también promueve la creación y es parte de nuestra identidad.

Notas

\section{1. http://foto-cassette.blogspot.com/}

\section{Bibliografía}

Baeza, M. (2006). Globalización y Homogeneización Cultural. Revista Sociedad Hoy. №10: [9-24].

Cruz, D. (2014). Catálogo concurso Matilde Pérez. Fundación telefónica.

lanni, O. (1996). Teorías de la Globalización. Madrid: Siglo XXI Editores.

Liesser, W. (2009). Arte digital. H. F. Ullman.

Manovich, L. (2001). El lenguaje de los nuevos medios. Paidós.

McLuhan, M. (1962). La galaxia Gutemberg. University of Toronto Press.

Mcluhan, M. (1967). El medio es el mensaje. Paidos.

Tribe, M. y Jana, R. (2009). Arte y nuevas tecnologías. Barcelona: Tachen.

Abstract: The essay approaches the relationship between art and technology not only from the historic and technical backgrounds that generates its development but from different other aspects. 
Key words: art - technology - culture - society.

Resumo: O ensaio é uma leitura da relação entre arte e tecnologia a partir dos antecedentes históricos e técnicos que gestaram seu desenvolvimento desde diferentes aristas.

Palavras chave: arte - tecnologia - cultura - sociedade. 